\title{
Phenotypic and DNA Relatedness between Nematode Symbionts and Clinical Strains of the Genus Photorhabdus (Enterobacteriaceae) $\dagger$
}

\author{
RAYMOND J. AKHURST, ${ }^{1 *}$ ROSLYN G. MOURANT, ${ }^{1}$ LUCIENNE BAUD, ${ }^{2}$ AND NOËL E. BOEMARE ${ }^{2}$ \\ Division of Entomology, Commonwealth Scientific and Industrial Research Organisation, Canberra ACT 2601, \\ Australia, ${ }^{1}$ and Laboratoire de Pathologie Comparé, Institut National de la Recherche Agronomique-Centre \\ National de la Recherche Scientifique Unité de Recherche Associée 2209, Université Montpellier II, \\ 34095 Montpellier Cedex 5, France ${ }^{2}$
}

\begin{abstract}
Bacterial strains isolated from wide ranges of nematode hosts and geographic sources and strains isolated from human clinical specimens were used to assess the taxonomic structure of the genus Photorhabdus. The following two methods were used: DNA relatedness and phenotypic characterization. Analysis of the DNA relatedness data revealed that all of the strains studied were congeneric and that the genus Photorhabdus is, on the basis of DNA relatedness data, more homogeneous than the other genus of nematode-symbiotic bacteria, the genus Xenorhabdus. In contrast to previous reports, only two DNA relatedness groups were identified in the genus Photorhabdus. These groups corresponded to the symbiotic strains and the clinical strains. There appeared to be some subgroups within the symbiotic strain group on the basis of the interactions of the strains with nematodes, which corresponded to some extent with the DNA relatedness data. However, there were significant ambiguities in the DNA relatedness data, and this group could not be subdivided on the basis of DNA relatedness data or phenotypic data. The distinct functional differences within and between the DNA relatedness groups of symbiotic Photorhabdus strains indicated that there are biologically significant subgroups within the genus Photorhabdus that cannot be defined at this time. Further investigation of the taxonomy of Photorhabdus by using different approaches and a suitably wide range of strains is recommended. However, it is clear that the clinical strains form a recognizable subgroup within the genus even though no formal subtaxon can be defined at this time.
\end{abstract}

Khan and Brooks (28) and Poinar et al. (34) reported the isolation of bioluminescent bacteria that were symbiotically associated with the insect-pathogenic nematodes Heterorhabditis bacteriophora (synonym, Heterorhabditis heliothidis [30]) and $H$. bacteriophora, respectively. These bacteria were subsequently classified in the genus Xenorhabdus along with the symbionts of nematodes of the family Steinernematidae and described as members of a new species, Xenorhabdus luminescens (40). Bacteria subsequently isolated from Heterorhabditis spp. $(3,6,7,32,33,38)$ and some isolates obtained from clinical sources (20) were also classified as $X$. luminescens strains. On the basis of phenotypic characteristics and DNA relatedness data, the creation of a new genus, the genus Photorhabdus, to accommodate the bacteria previously identified as $X$. luminescens was proposed by Boemare et al. (14); only one Photorhabdus species, Photorhabdus luminescens, was recognized.

The results of several studies have indicated that $P$. luminescens should be divided into several groups. Initially, four DNA relatedness groups were recognized (24) in the genus Photorhabdus, and later a fifth group was recognized (20). Significant dissimilarities between isolates of $P$. luminescens have also been revealed by $16 \mathrm{~S}$ rRNA studies (35). In addition, there are substantial differences in the interactions between $P$. luminescens and Heterorhabditis spp. in monoxenic cultures; the symbionts of some nematode isolates are not able to support cultures of other isolates $(8,22,25)$. However, despite the

\footnotetext{
* Corresponding author. Mailing address: Division of Entomology, Commonwealth Scientific and Industrial Research Organisation, GPO Box 1700, Canberra ACT 2601, Australia.

$\uparrow$ Dedicated to Lucienne Baud (deceased 9 August 1994) in memory of her contribution.
}

obvious differences between some Photorhabdus strains, the numbers of isolates used in the previous studies have been insufficient to permit subdivision of the genus.

One of the difficulties in establishing a taxonomy for these bacteria arises from phase variation. Akhurst (1a) showed that the symbionts of Steinernema and Heterorhabditis species occur in two phases that differ in their ability to support reproduction of the nematodes. The two phases of each Xenorhabdus and Photorhabdus species have been shown to vary in many characters (dye adsorption, antibiotic production, phospholipase activity, inclusion proteins, fimbriae, specific activities of respiratory enzymes) $(8,37)$; the two phases of Photorhabdus strains also differ in bioluminescence and pigmentation $(6,7,12)$. The differences between the two phases are so marked that a numerical taxonomic study revealed that the phase characters strongly distorted the analysis and had to be discarded.

In this study we addressed the problems posed to previous workers by the limited range of strains tested and the differences between phases by using both phases of Photorhabdus strains isolated from wide ranges of nematode host species and geographical sources, including some clinical specimens, to test the hypothesis that the clinical strains form a subtaxon within the genus Photorhabdus.

\section{MATERIALS AND METHODS}

Bacterial isolates. Bacteria were obtained from broad ranges of nematode host species and geographical sources and from clinical specimens. The sources of the bacterial isolates used are listed in Table 1. Usually, phase I isolates were obtained directly from the nematode host $(7)$; the strain $\mathrm{Hb}^{\mathrm{T}}(\mathrm{T}=$ type strain) culture was established from a single colony of strain ATCC $29999^{\mathrm{T}}$, which, like ATCC 29304, was obtained from the American Type Culture Collection, Rockville, Md. Phase II isolates were obtained from in vitro cultures of phase I isolates by repeated clonal selection of flat, nongranulated, nonmucoid colonies from stationary-phase nutrient broth cultures plated onto nutrient agar. Clones were considered phase II isolates only if, after serial subculture, they exhibited no 
TABLE 1. Sources of $P$. luminescens strains used in this study

\begin{tabular}{|c|c|c|c|c|}
\hline Strain & Other designation(s) & Geographical source & Nematode host species & Reference(s) \\
\hline ATCC 29304 & NC-19 & United States & Heterorhabditis bacteriophora & $20,24,28$ \\
\hline $\mathrm{C} 1$ & $\mathrm{C}, \mathrm{NC1}$ & United States & Heterorhabditis bacteriophora $a^{a}$ & 3,4 \\
\hline $\mathrm{C} 8404$ & & People's Republic of China & Heterorhabditis sp. ${ }^{b}$ & 4 \\
\hline C8406 & & People's Republic of China & Heterorhabditis bacteriophora ${ }^{c}$ & 4 \\
\hline D1 & $\mathrm{D}$ & Australia & Heterorhabditis sp. $^{b}$ & 3 \\
\hline Habana & & Cuba & Heterorhabditis sp. & 9 \\
\hline $\mathrm{Hb}^{\mathrm{Td}}$ & ATCC $29999^{\mathrm{T}}, \mathrm{Hb}^{\mathrm{T}}$ & Australia & Heterorhabditis bacteriophorac & 34 \\
\hline $\mathrm{Hm}$ & & United States & Heterorhabditis bacteriophora & 12 \\
\hline HI & & Italy & Heterorhabditis sp. & 7 \\
\hline HF85 & & The Netherlands & Heterorhabditis megidis & 38 \\
\hline HL81 & & The Netherlands & Heterorhabditis megidis & 38 \\
\hline HFR86 & & The Netherlands & Heterorhabditis megidis & $40 \mathrm{a}$ \\
\hline HP88 & & United States & Heterorhabditis sp. ${ }^{a}$ & 32 \\
\hline HV16 & V16 & Australia & Heterorhabditis sp. ${ }^{a}$ & 4 \\
\hline HW79 & & The Netherlands & Heterorhabditis megidis & 38 \\
\hline ItH211 & & Italy & Heterorhabditis sp. & 16 \\
\hline K80 & & Argentina & Heterorhabditis sp. & 18 \\
\hline K81 & & Guadeloupe & Heterorhabditis sp. & 15 \\
\hline Meg & & United States & Heterorhabditis megidis & 33 \\
\hline NC162 & & United States & Heterorhabditis bacteriophora & 4 \\
\hline $\mathrm{NZH}$ & & New Zealand & Heterorhabditis zealandica & 4,41 \\
\hline Q614 & HQ614 & Australia & Heterorhabditis sp. ${ }^{e}$ & $4-6$ \\
\hline T327 & & Australia & Heterorhabditis zealandica & 4 \\
\hline Tetuan & & Cuba & Heterorhabditis sp. $f$ & 4,10 \\
\hline X1Lit & & Lithuania & Heterorhabditis sp. ${ }^{g}$ & 4 \\
\hline X1Nach & & Russia & Heterorhabditis sp.g & 4 \\
\hline $1216-79$ & ATCC 43948 & United States & None & 20 \\
\hline $2407-88$ & ATCC 43952 & United States & None & 20 \\
\hline $2617-87$ & ATCC 43951 & United States & None & 20 \\
\hline $3105-77$ & ATCC 43949 & United States & None & 20 \\
\hline $3265-86$ & ATCC 43950 & United States & None & 20 \\
\hline
\end{tabular}

${ }^{a}$ The results of cross-breeding and satellite DNA analyses indicate that Heterorhabditis sp. strain HP88 is not a Heterorhabditis bacteriophora, Heterorhabditis indicus, or Heterorhabditis megidis strain $(1,17)$. Joyce et al. $(27)$ have suggested that this strain belongs to the same subgroup of the Heterorhabditis bacteriophora species complex as strains $\mathrm{NC} 1$ and $\mathrm{HV} 16$.

${ }^{b}$ Heterorhabditis sp. strains D1 and C8404 were assigned to the same (undescribed) species on the basis of isozyme data (4).

${ }^{c}$ An isozyme analysis of strains $\mathrm{Hb}$ and $\mathrm{C} 8406$ revealed that they are identical for 10 discriminating enzymes (4).

${ }^{d} \mathrm{Hb}^{\mathrm{T}}$ was clonally derived from ATCC $29999^{\mathrm{T}}$.

e Poinar (30) considered Q614 conspecific with NZH and T327 and to be a Heterorhabditis zealandica strain. However, see the compatibility data in Table 4.

${ }^{f}$ Arteaga-Hernandez and Mracek (10) found no morphological differences between the Tetuan and $\mathrm{P}_{2} \mathrm{M}$ strains of Heterorhabditis sp., and Joyce et al. (27) identified $\mathrm{P}_{2} \mathrm{M}$ as a Heterorhabditis indicus strain on the basis of cross-breeding data and its restriction fragment length polymorphism profile. However, morphological characterization of Heterorhabditis strains has often been misleading, and so identification of the Tetuan strain as a Heterorhabditis indicus strain cannot be made with certainty.

${ }^{g}$ Isozyme analysis of Heterorhabditis sp. strains X1Nach and X1Lit revealed that these strains are identical for 10 discriminating enzymes (4). Poinar (30) considered these strains conspecific with NZH, Q614, and T327 and to be Heterorhabditis zealandica strains.

evidence of antibiotic production or dye adsorption from MacConkey agar and did not regenerate phase $\mathbf{I}$ or intermediate variants $(8,22,26)$.

Five isolates $(1216-79,2407-88,2617-87,3105-77$, and 3265-86) were not associated with nematodes but were obtained from clinical sources (20); these isolates, which were provided by J. J. Farmer, Jr. (Centers for Disease Control and Prevention, Atlanta, Ga.), were identified as phase II isolates by their colony and cell morphology and by their lack of antibiotic production and dye adsorption. Phase I isolates of these strains have never been reported and could not be detected in this study. Except for the clinical isolates, the suffixes of the designations indicate phases (e.g., isolates $\mathrm{Hb} / 1$ and $\mathrm{Hb} / 2$ are phase I and phase II variants of isolate $\mathrm{Hb}^{\mathrm{T}}$, respectively), as previously described (13).

The DNA relatedness analysis component of the study was conducted in Australia, and the phenotypic analysis component was performed in France. At the beginning of the study, subcultures of each isolate were exchanged to ensure that the French and Australian groups worked with the same material. Reference cultures were stored in $17 \%(\mathrm{vol} / \mathrm{vol})$ glycerol broth at $-70^{\circ} \mathrm{C}$. Stock cultures were maintained and monitored for phase variation as described by Boemare and Akhurst (13).

DNA relatedness. The methods used to purify bacterial DNA, hybridize DNA, and estimate DNA relatedness were those used by Boemare et al. (14). For 21 of 30 isolates DNA was purified only from phase I cultures. For isolates $\mathrm{Hb}^{\mathrm{T}}, \mathrm{Cl}$, Meg, K81, and T327, DNA was purified from both phase I and phase II cultures. As the clinical isolates did not occur as phase I organisms, DNA was purified from phase II cultures of strains 1216-79, 2617-87, 3105-77, and 3265-86.

DNA labelling with ${ }^{32} \mathrm{P}$, reassociating DNA by a hydroxyapatite method at $60^{\circ} \mathrm{C}$, and estimating DNA relatedness were carried out as described by Boemare et al. (14). Hybridization of phase I and phase II DNAs was performed with isolates $\mathrm{Hb}^{\mathrm{T}}$, Meg, and $\mathrm{K} 81$. Reciprocal hybridizations (i.e., hybridizations in which first one isolate and then the other was used as the labelled isolate) were performed with 25 pairs of isolates. Replicate hybridization experiments were performed with many but not all pairs. For the pairs for which replicate hybridization experiments were performed a one-way analysis of variance was used to determine the significance of differences.

Phenotypic characterization. Most tests were conducted by using API 20E, API 20NE, API 50CH, API 50AO, and API 50AA strips (Biomérieux) as described previously (13). Tests for catalase activity, bioluminescence, dye adsorption from MacConkey agar, and phospholipase (lecithinase) activity were conducted by the methods employed by Akhurst (3). The methods of Boemare and Akhurst (13) were used to test for production of phenylpyruvic acid from phenylalanine, production of indolepyruvic acid from tryptophan, lipolysis of Tween 20 , Tween 40 , Tween 60 . Tween 80 , and Tween 85 , and proteolysis of gelatin and casein. Adsorption of bromothymol blue was assessed on nutrient agar supplemented with $0.004 \%(\mathrm{wt} / \mathrm{vol})$ triphenyltetrazolium chloride and $0.0025 \%(\mathrm{wt} / \mathrm{vol})$ bromothymol blue (NBTA medium) (1a). Pigmentation was determined by examining colonies on nutrient agar after incubation for 5 days. Antimicrobial activity was determined by the method of Akhurst (2), using Micrococcus luteus as the indicator organism. Cells from nutrient or Luria-Bertani (29) broth cultures were suspended in $0.25 \times$ Ringer's solution and examined by phase-contrast microscopy for the presence of inclusions. All tests were conducted in duplicate at $28^{\circ} \mathrm{C}$.

Hemolysis was determined on blood agar ( $15 \mathrm{~g}$ of proteose peptone, $2.5 \mathrm{~g}$ of liver hydrolysate, $5 \mathrm{~g}$ of yeast extract, $5 \mathrm{~g}$ of $\mathrm{NaCl}, 12 \mathrm{~g}$ of agar, water to a volume of 1 liter, $10 \%$ sheep or horse blood) after 5 days of incubation at $28^{\circ} \mathrm{C}$. Hemo- 
TABLE 2. Levels of DNA relatedness of Photorhabdus strains

\begin{tabular}{|c|c|c|c|c|c|c|c|c|c|c|c|}
\hline \multirow{2}{*}{$\begin{array}{c}\text { Source of } \\
\text { unlabelled DNA }\end{array}$} & \multicolumn{11}{|c|}{ RBR $(\%)$ with ${ }^{32}$ P-labelled DNA from strain: } \\
\hline & $\mathrm{Hb}^{\mathrm{T}}$ & $\mathrm{NC} 162$ & D1 & Tetuan & ItH211 & $\mathrm{C} 1$ & Meg & X1Nach & NZH & Q614 & $\overline{1216-79}$ \\
\hline $\mathrm{Hb}^{\mathrm{T}}$ & & 61 & 67 & 67 & & & & 48 & 45 & 47 & \\
\hline $\mathrm{Hm}$ & 109 & 60 & 77 & 63 & 42 & 51 & 57 & 49 & 57 & 50 & 52 \\
\hline C 8404 & 77 & & 82 & & & 43 & 50 & & 59 & 51 & \\
\hline C8406 & 77 & & 64 & & & 37 & 59 & & 48 & 62 & \\
\hline $\mathrm{NC} 162$ & 75 & & 59 & & 48 & 47 & 39 & & 40 & 59 & \\
\hline D1 & 71 & 55 & & 85 & & 38 & 57 & & 43 & 49 & 49 \\
\hline Tetuan & 66 & & 96 & & 41 & 44 & 50 & & 46 & 47 & 53 \\
\hline K81 & 62 & & 85 & & 44 & 54 & 53 & & 44 & 54 & \\
\hline HP88 & 71 & & & & & 44 & 51 & & 51 & 65 & \\
\hline K80 & 57 & & 65 & & & 36 & 56 & & 54 & 52 & \\
\hline HV16 & 59 & 63 & 49 & 45 & 38 & 29 & 41 & 40 & 30 & 36 & 45 \\
\hline $\mathrm{HI}$ & 56 & & 61 & & 43 & 43 & 40 & & 43 & 49 & \\
\hline ItH211 & 59 & 41 & 46 & & & 49 & 61 & & 49 & 52 & \\
\hline $\mathrm{C} 1$ & 32 & & 51 & 53 & & & 75 & 68 & 66 & 49 & \\
\hline Habana & 57 & & 43 & & & 93 & 88 & & 70 & 55 & \\
\hline Meg & 32 & & 50 & & & 91 & & 71 & 58 & 52 & 53 \\
\hline HW79 & 44 & & 44 & & & 73 & 76 & & 65 & 56 & \\
\hline HFR86 & 49 & & & & & 73 & 68 & & 79 & 48 & \\
\hline HL81 & 52 & & 48 & & & 60 & 78 & & 75 & 56 & \\
\hline HF85 & 55 & & 34 & & & 66 & 69 & & 71 & 55 & \\
\hline X1Nach & 48 & 43 & 48 & 50 & & 65 & 73 & & 51 & 55 & 54 \\
\hline X1Lit & 63 & & & 48 & & 58 & & 102 & 61 & 45 & \\
\hline NZH & 47 & & 41 & & & 64 & 67 & 70 & & & \\
\hline T327 & 45 & & 47 & & & 56 & 72 & 67 & 82 & 54 & 55 \\
\hline Q614 & 44 & & 48 & & & 38 & 57 & & 49 & & 58 \\
\hline $1216-79$ & 44 & 33 & 48 & & & 50 & 60 & & 56 & 50 & \\
\hline $2407-88$ & & & & & & & 50 & & & 55 & 103 \\
\hline $2617-87$ & 46 & & 44 & & & 41 & & & 41 & 50 & 100 \\
\hline $3105-77$ & & & 41 & & & 29 & 55 & & & 55 & 107 \\
\hline $3265-86$ & & & 44 & 43 & & & & & & 57 & 100 \\
\hline
\end{tabular}

lysis was also determined on tryptic soy agar supplemented with $5 \%$ sheep blood (Oxoid) at $25^{\circ} \mathrm{C}$

Temperature tolerance was determined by suspending cells from 2- to 3-day nutrient agar cultures $\left(28^{\circ} \mathrm{C}\right)$ in Luria-Bertani broth (29) and spotting 5- $\mu$ l aliquots onto duplicate nutrient agar plates; for each strain one plate was incubated at $28^{\circ} \mathrm{C}$ and the other plate was incubated at $37^{\circ} \mathrm{C}$. The plates were examined for growth daily for 5 days.

The phenotypic data were examined by performing a numerical analysis. The Jaccard coefficient (39) was used to calculate levels of similarity, and various clustering strategies (L\&W flexible, unpaired group mean averages, ISS flexible) were applied. The whole data set, the whole data set minus the data for the major-phase characters, the whole data set minus the data for the major- and minor-phase characters, the phase I data set, and the phase II data set were analyzed. The data were also analyzed by using a strategy adopted for the genus Xenorhabdus (7) in which the data for both phases of each strain were combined and the strain was scored positive for a character if either phase was positive and negative only if both phases were negative.

Compatibility of Heterorhabditis and Photorhabdus strains. Various combinations of Heterorhabditis and Photorhabdus strains were grown in monoxenic cultures to assess their compatibility. For each test, the Heterorhabditis strain tested was cultured with its natural symbiont as a positive control and with Photorhabdus strains isolated from other Heterorhabditis strains.

Autoclaved pieces of polyether polyurethane sponge lightly coated with Bedding's medium (11) were placed on nutrient agar slants and inoculated with 1-ml portions of overnight cultures of Photorhabdus strains. Each sponge-containing slant was incubated at $28^{\circ} \mathrm{C}$ for 3 days to ensure complete coverage of the sponge and agar by the inoculated strain, which prevented growth of any Photorhabdus cells carried inside the infective juveniles. Heterorhabditis infective juveniles were surface sterilized by immersion in $0.1 \%$ thimerosal for $1 \mathrm{~h}$ and washed in sterile distilled water, and about 100 were added to each slant. The cultures were incubated at $28^{\circ} \mathrm{C}$, and those cultures in which a new generation of infective juveniles was produced were subcultured by using the same procedure involving preinoculation of medium and surface sterilization of infective juveniles. Combinations were considered compatible when reproduction continued in the second subculture.

\section{RESULTS}

DNA relatedness. Levels of DNA relatedness were estimated for 172 pairs of isolates on the basis of the results of 286 hybridization reactions (Table 2). There was no significant $(P<0.05)$ difference from a $100 \%$ relative binding ratio (RBR) for phase I and phase II cultures of strains $\mathrm{Hb}^{\mathrm{T}}$, Meg, and $\mathrm{K} 81$ (106, 104, and 109\%, respectively). There was also no significant $(P<0.05)$ difference in RBR for the reciprocal hybridizations performed with any of the 25 pairs tested or for hybridizations between any strain and the two phases of strains $\mathrm{Hb}^{\mathrm{T}}$, C1, Meg, K81, and T327.

Strains C1 and ATCC 29304, which were isolated from the same nematode strain in different laboratories in 1977 and 1983, had an estimated RBR of $101 \%$. Several other pairs of strains derived from different nematode strains were found to exhibit $100 \%$ relatedness (e.g., strains $\mathrm{Hb}^{\mathrm{T}}$ and $\mathrm{Hm}$, strains $\mathrm{X} 1 \mathrm{Nach}$ and X1Lit, and pairs of clinical isolates).

Phenotypic characterization. Both phases of all strains were positive for catalase activity and for assimilation of glucose, fructose, mannose, $\mathrm{N}$-acetylglucosamine, fumarate, and L-glutamate. Both phases of all strains were negative for oxidase activity, nitrate reductase activity, the $o$-nitrophenyl- $\beta$-D-galactopyranoside- $p$-nitrophenyl- $\beta$-D-galactopyranoside test, arginine dehydrogenase activity, lysine decarboxylase activity, ornithine decarboxylase activity, $\mathrm{H}_{2} \mathrm{~S}$ production, and assimilation of erythritol, D-arabinose, L-arabinose, L-xylose, adonitol, methyl-D-xyloside, galactose, sorbose, rhamnose, dulcitol, 
sorbitol, methyl-D-mannoside, methyl-D-glucoside, cellobiose, lactose, melibiose, inulin, melezitose, raffinose, starch, glycogen, xylitol, gentiobiose, D-turanose, D-xylose, D-tagatose, Dfucose, D-arabitol, L-arabitol, 2-ketogluconate, 5-ketogluconate, butyrate, isobutyrate, isovalerate, $N$-caproate, heptanoate, caprylate, pelargonate, caprate, malonate, maleate, glutarate, adipate, pimelate, suberate, azelate, sebacate, glycolate, DL-lactate, DL-3-hydroxybutyrate, D-tartrate, mesotartrate, levulinate, 2-ketoglutarate, citraconate, itaconate, mesaconate, phenylacetate, benzoate, 2-hydroxybenzoate, 3-hydroxybenzoate, 4-hydroxybenzoate, D-mandelate, L-mandelate, phthalate, isophthalate, terephthalate, L-leucine, L-isoleucine, L-norleucine, L-valine, DL-norvaline, DL-2-aminobutyrate, L-methionine, L-phenylalanine, D-tryptophan, L-tryptophan, trigonelline, L-lysine, L-citrulline, betaine, creatine, $\beta$-alanine, DL-3-aminobutyrate, DL-4-aminobutyrate, DL-5aminobutyrate, 2-aminobenzoate, 3-aminobenzoate, 4-aminobenzoate, urea, acetamide, sarcosine, ethylamine, butylamine, amylamine, ethanolamine, benzylamine, diaminobutane, spermine, histamine, tryptamine, glycine, and DL-kynurenine.

The data for discriminatory phenotypic characters are shown in Table 3. All strains were highly proteolytic and lipolytic (for Tween 20), at least in phase I. Protoplasmic inclusions were produced by phase I organisms in all strains and to a lesser extent or not at all by phase II organisms. Bioluminescence was detected by eye in the clinical strains and in phase I cultures of all symbiotic strains except Q614, for which bioluminescence could not be detected even with a scintillation counter.

Phase I isolates of all strains adsorbed dyes from MacConkey agar and NBTA medium and exhibited antibiotic activity against $M$. luteus; phase II isolates were all negative for these characters. There were differences in proteolytic activity as determined with casein and gelatin for only 6 of the 53 isolates.

The unusual hemolytic reaction reported by Farmer et al. (20) was observed for both the clinical strains and some symbiotic strains on sheep blood agar at 25 and $28^{\circ} \mathrm{C}$; this unusual reaction was more common at $25^{\circ} \mathrm{C}$ than at $28^{\circ} \mathrm{C}$ (Table 3 ). Only six isolates produced the unusual hemolytic reaction on horse blood agar at $28^{\circ} \mathrm{C}$ and none of the clinical strains exhibited this reaction under these conditions. In general, the unusual hemolytic reaction consisted of partial hemolysis around the colony, as demonstrated by greening associated with the production of biliverdin and annular clearing of the medium (total hemolysis?) at a distance of $10 \mathrm{~mm}$ or so from the colony. In a few isolates (Q614/1, HP88/2, and HV16/2), the annular clearing was overtaken after 3 or 4 days by total hemolysis that spread outward from the colony.

Numerical analysis of the phenotypic data from this study revealed that phase I variants of Photorhabdus isolates were generally more similar to each other than to the phase II variants of the same strains (Fig. 1), as previously demonstrated for Xenorhabdus isolates (7). Further examination revealed that antibiosis, dye binding, and phospholipase activity were the major phase-related characters in Photorhabdus and that these characters differentiated phase I variants from phase II variants in 23 or 24 of the 24 strains for which both phases were available. Differential pigmentation, bioluminescence, inclusion proteins, and partial hemolysis of sheep blood were also significant phase-related characters which differentiated the two phases of 15 to 19 of the 24 symbiotic strains. However, numerical analysis of the data after exclusion of these characters showed that there was still a slight tendency for isolates to cluster by phase prior to clustering as strains. Only 9 of the 65 discriminative characters (Table 3 ) did not differentiate the phases of any strain.

Numerical analysis of the phase I data set, the phase II data set, and the combined data set did not produce any groups that correlated with either the DNA relatedness data or source (e.g., nematode host species).

Compatibility of Heterorhabditis and Photorhabdus strains. Testing combinations of various Heterorhabditis and Photorhabdus strains in vitro revealed some significant differences between strains (Table 4). There was no correlation between compatibility profile and DNA relatedness. Strains $\mathrm{Hb}^{\mathrm{T}}$ and HI, which had an RBR of 56\% (Table 2), had identical compatibility profiles, as did strains NZH and T327 (RBR, 82\%), but strains $\mathrm{Hb}^{\mathrm{T}}$ and $\mathrm{D} 1$ (RBR, 67 to $70 \%$ ) had very different compatibility profiles.

\section{DISCUSSION}

This study showed that the strains of $P$. luminescens that are symbiotically associated with entomopathogenic nematodes can be distinguished from the clinical $P$. luminescens strains (20) by both phenotypic and DNA relatedness data. However, the clear functional differences in nematode-bacterium interactions among the symbiotic strains (Table 4) did not correlate with either phenotypic or DNA relatedness data. Only two groups, the symbionts and the clinical strains, could be identified by either phenotypic or DNA relatedness data. The hypothesis that there are five DNA relatedness groups in the genus Photorhabdus $(20,24)$ was disproved by the results of this study, which involved a larger number of Photorhabdus strains from wider ranges of host species and geographical sources than previous studies.

Phenotypic characterization. Farmer et al. (20) described an unusual hemolytic reaction that occurred in clinical strains when they were grown at $25^{\circ} \mathrm{C}$, although not when they were grown at $37^{\circ} \mathrm{C}$. This type of hemolysis, which is expressed as a thin band at some distance (ca. $10 \mathrm{~mm}$ ) from each bacterial colony, generally with partial hemolysis immediately adjacent to the colony, was detected in some strains in the present study and was confirmed to be temperature sensitive. Farmer et al. (20) proposed that this reaction should be designated "Xenorhabdus luminescens hemolysis." However, as this type of hemolysis does not occur with the majority of $P$. luminescens strains and it has been proposed that $X$. luminescens should be transferred to the genus Photorhabdus (14), this term is not appropriate. We propose that the reaction should be designated "annular hemolysis" because it produces an annulus around each colony.

The analysis of the phenotypic data was complicated by the phase variation $(1 \mathrm{a}, 13)$ and colonial heterogeneity $(8,19,22$, $23,26)$ that occur in the symbiotic Photorhabdus strains and are correlated with biochemical characters often used in phenotypic taxonomy. It was further complicated by the absence of any phase I variants of the clinical strains. In the genus $\mathrm{Xe}$ norhabdus the phase problem was overcome by combining the data for the two phases and scoring a strain positive if either or both phases gave a positive response and negative only if both phases gave a negative response (7). However, this was not an option in this study because no phase I data could be obtained for the clinical strains, which did not produce as phase I variants. The taxonomy of the genus Photorhabdus had to be based on the results of a comparison of data that did not include data for the major phase-related phenotypic characters, and the resulting data set was too small to allow a meaningful numerical analysis. The use of only the extreme variants of each strain may have limited this study. A much larger phenotypic study performed with a range of variants for a suitably large number of strains of diverse origin may be required to establish a reliable taxonomy based on phenotypic data. 
$\begin{array}{llllllllllllllllllllllllllllllllllllllll}1 & 1 & 1 & 1 & 1 & 1 & 1 & 1 & 3 & 1 & 1 & 1 & 1 & 1 & 1 & 1 & 1 & 1 & + & + & 1 & 1 & 1 & 1 & 1 & 1 & 1 & 1 & 1 & 1 & 1 & 1 & 1 & + & 1 & 1 & 1 & 1 & 1 & 1\end{array}$

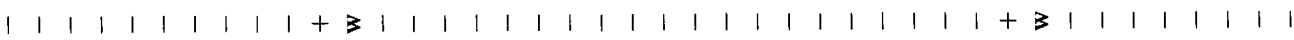

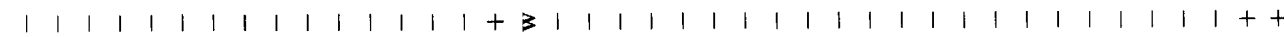

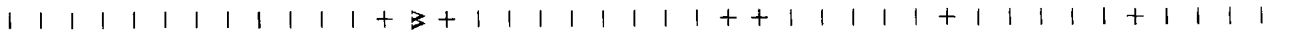

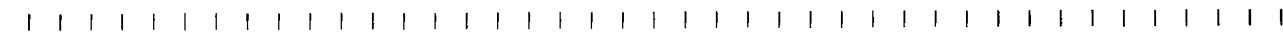
$\begin{array}{lllllllllllllllllllllllllllllllllllllll}1 & 1 & 1 & 1 & 1 & 1 & 1 & 1 & 1 & 1 & 1 & 1 & 1 & 1 & 1 & 1 & 1 & 1 & 1 & 1 & 1 & 3 & + & 1 & 1 & 1 & 1\end{array}$

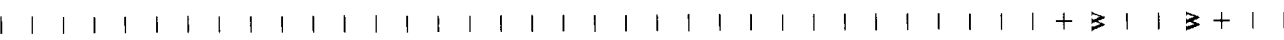

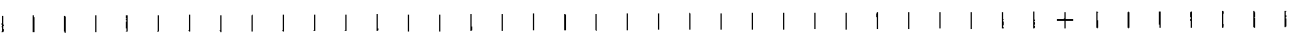

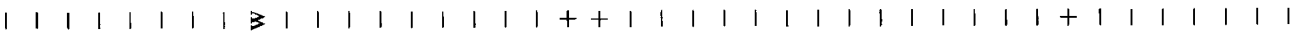
$+++3+++++++++++3++++3++1++++++++13++++\begin{array}{llll}1 & 1 & 1\end{array}$

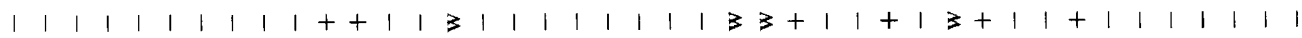
$++++++1|1++++++++++++1| 133++11++33++3++1 \mid+t$

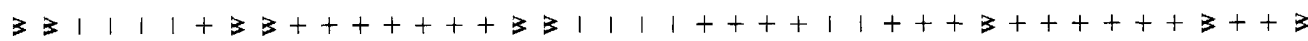

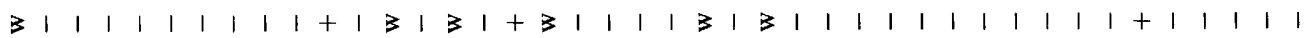
$++1|++1| 1311+++31 \quad 1 \quad 1 \quad 1 \quad 1++++1 \quad 1+++333+3+33311$

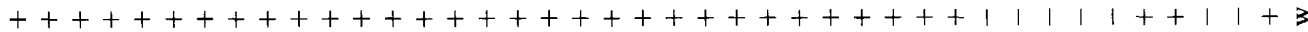

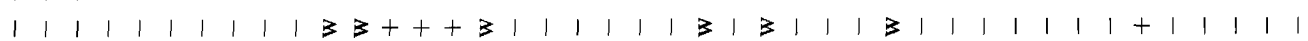
$+3 t+++1 \mid 1+++++++3++++11+++3++++++11+3+1+++t$ $t+333++1+++++++++31 \quad 131+1++++1+++1 \mid++++1+1+3$ $31|1+t+33333+1+t+t+t+1+31|+t+3+1|1| 3+++1+3+$ $1|++1| 1+++++++++++++++++++++++++33+++++1 \mid+t$

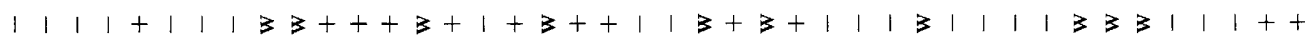

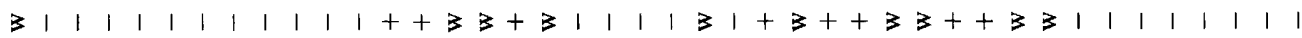

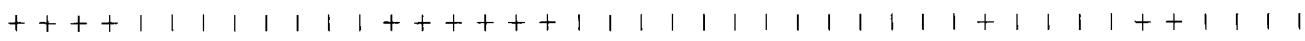
$++++33+++++++++1+311++1|1| 1++++1111+1+t++11$ $++++t++3++++++++++1 \mid 1+1+++++33++3+3++++++11$ $+3+333+1+++t+++3 t+++11+++++++++3+++3++3311$ $+1+++++++++++++++11++++++++++++11+1+t+t+t$ $t++3 t+++++33+++t+++t++++33+++++1|1|+1++3+3 t$

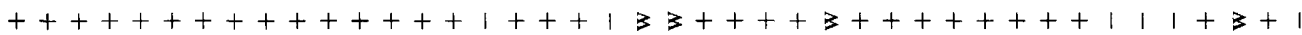
$++1 \mid+++1+++1+++3+3+1+1+++3+++++3+3+++3++11$ $+++3+++++++++++++++3+++++++3+++++++++++++3$ $++++++3+++++++++++++3+++++++++++3+++++1 \mid 3+$ $++++t+++++++++++++1 \mid 1++++++++++++++1+++++1$

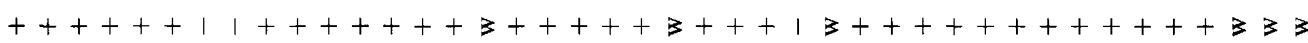
$+++++++++++++++++11+3+++++++++++++++++t+3$ $1|1| 1|1+1+t+1 \leqslant 1+1+1+1+1| 1|1| 1|1+1| 1|1| 1 \leqslant 1 \leqslant 1 \leqslant 1$

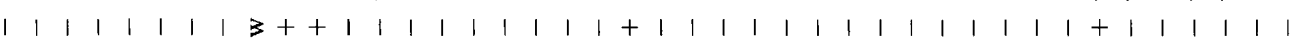
$|1| 1++1 \geqslant+1+1|1| 1+1++1|+3+1| 1++1 \mid 1+1+3 \geqslant 131++11$ $31+1 \leqslant 1 \leqslant 1|1| 1+1+3++1 \leqslant 1+1 \leqslant 1 \leqslant 1 \leqslant 1+1 \leqslant 1+31+++3 \geqslant 1$

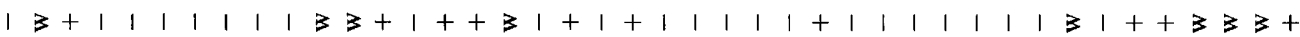

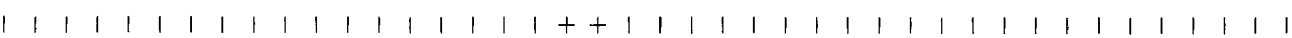
$+++1+1+1+1+111++++11+++++1+1+1 \quad 1 \quad 1 \quad 1 \quad 1+++++11$

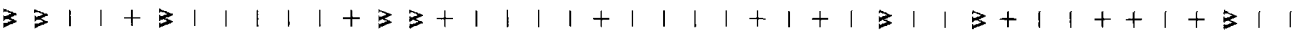

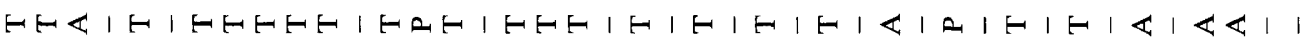

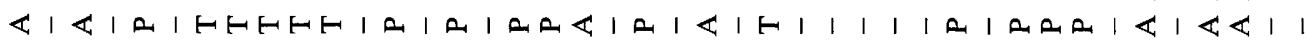

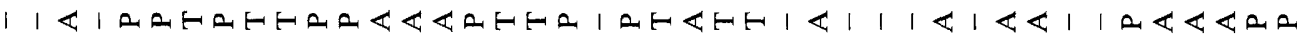

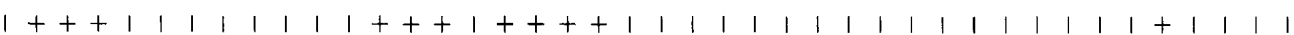
$+++3+++++++1+++++++1+++++3+1+++++++1++++1+$ $+++1++++++++++++++11+++++1+1+1+++++1++++1+$ $+1+1++++3++1+3+1++11+3+311++++33+++1+1+1++$ $+1+1+++3+++1+3+1++1 \mid 1+1+31 \leqslant 1+133+++1+3+1++$ $+1+++++3+++1+1|1|++++1+3+1|1| 3+1++31+1+1++$ $+1+1+++3 t++1 \geqslant 1+1+++++++1+1++++31+++1+1+1++$ $+++1+++1+++1+3+++++++1+++1+++++3+++1++++++$ $+3+1+1+3+1+1+1+1+++1+3+1+1+3+1+++1+1+++1++$ $+1+1+1+1+3+1+1+1+1+1+1+3+1+1+3+1+3+1+1+3+1$ $+1+1+1+1+++1+++1+1+1+1+++1+1+++1+1+++1+1+1$ $+1+1+1+1+1+1+1+1+1+1+1+3 \geqslant 1+1+1+1+1+1+1+1+1$ $+1+1+1+1+1+1+1+1+1+1+1+1+1+1+1+131+1+1+1+1$ $+1+1+1+1+1+1+1+1+1+1+1+1+1+1+1+1+1+1+1+1+1$ 


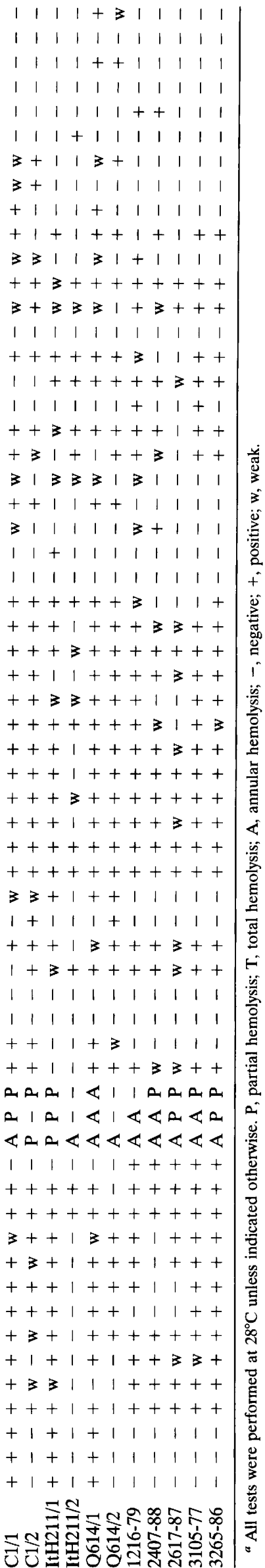

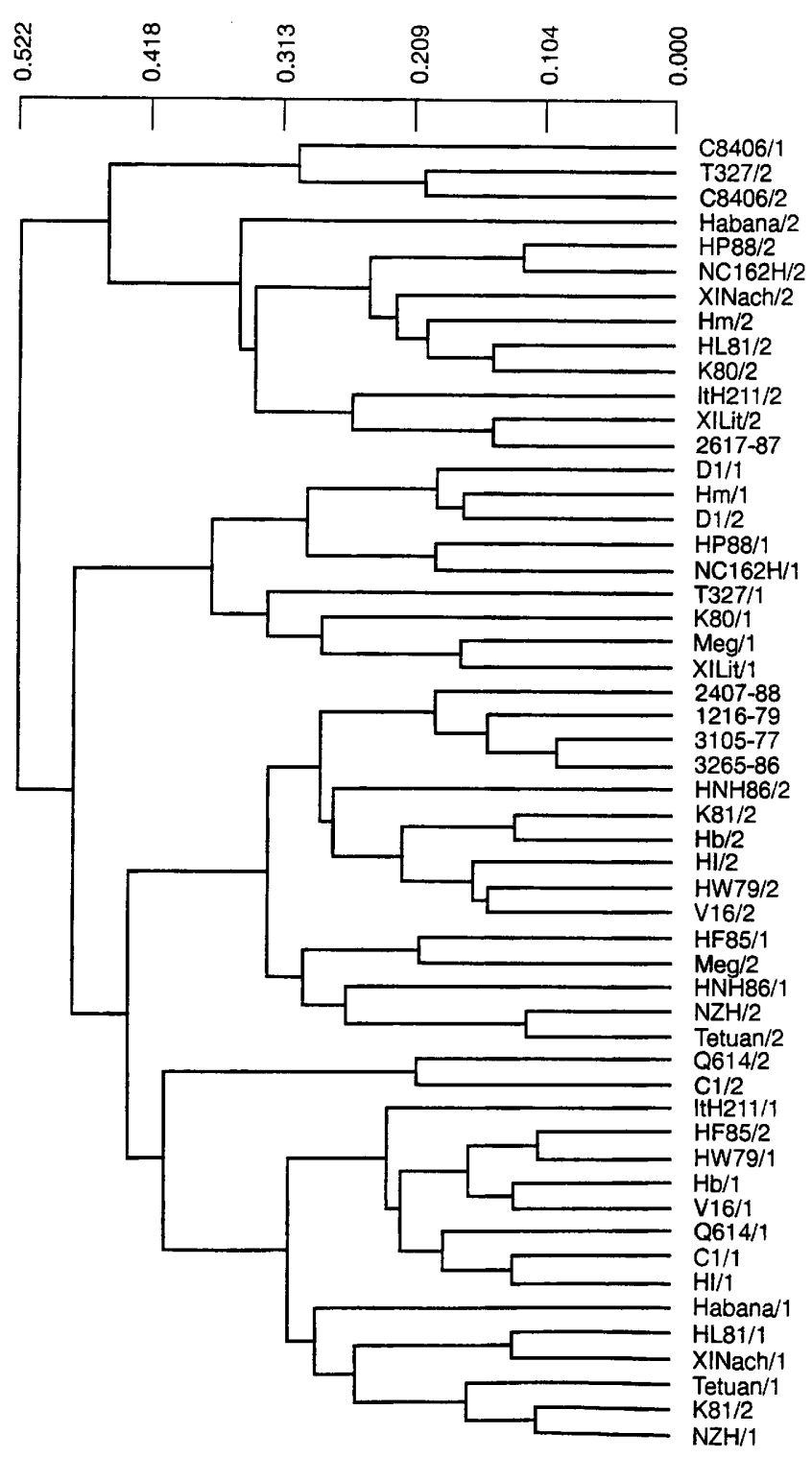

FIG. 1. Numerical analysis of phenotypic data for Photorhabdus isolates showing the significance of phase-related characters. Similarities calculated with the Jaccard coefficient were clustered by using the furthest-neighbor strategy.

Notwithstanding the problems described above, it was possible to differentiate the symbiotic strains from the clinical strains. The two groups were distinguishable by 11 characters; for 5 of these characters the five clinical strains were all negative and the symbiotic strains were variable (indole, indolepyruvic acid, assimilation of mannitol and L-fucose, and DNase activity), for 5 characters the clinical strains were all positive and the symbiotic strains were variable (esculin hydrolysis, Simmons citrate, growth at $37^{\circ} \mathrm{C}$, urease activity, annular hemolysis on sheep blood at $25^{\circ} \mathrm{C}$ ), and for 1 character (assimilation of aconitate) the symbiotic strains were all negative and the clinical strains were variable.

DNA relatedness. The DNA relatedness data also indicated that there is a difference between the symbiotic strains and the clinical strains (Table 2). However, the levels of relatedness between the clinical strains and some symbiotic strains were greater than the levels of relatedness between symbiotic strains; strain Meg had RBR of 50 to $60 \%$ with the clinical strains but RBR of 32 to $91 \%$ with the symbiotic strains. These higher RBR with the clinical strains than with some of the 
TABLE 4. Incompatibility of some Heterorhabditis and Photorhabdus strains in in vitro culture

\begin{tabular}{|c|c|c|c|c|c|c|c|c|}
\hline \multirow{2}{*}{ Strain } & \multicolumn{8}{|c|}{ Compatibility with the following Photorhabdus strains: } \\
\hline & $\mathrm{Hb}^{\mathrm{T}}$ & $\mathrm{Hm}$ & $\mathrm{C} 1$ & $\mathrm{HI}$ & D1 & NZH & $\mathrm{T} 327$ & Q614 \\
\hline Heterorhabditis bacteriophora $\mathrm{Hb}$ & + & + & + & + & - & + & - & - \\
\hline Heterorhabditis bacteriophora $\mathrm{C} 1$ & + & + & + & + & - & + & + & - \\
\hline Heterorhabditis sp. strain HI & + & + & + & + & - & + & - & - \\
\hline Heterorhabditis sp. strain D1 & - & - & - & - & + & - & - & - \\
\hline Heterorhabditis zealandica $\mathrm{NZH}$ & - & - & + & - & - & + & + & + \\
\hline Heterorhabditis zealandica T327 & - & - & + & - & - & + & + & + \\
\hline Heterorhabditis sp. strain Q614 & - & - & - & - & - & + & + & + \\
\hline
\end{tabular}

symbiotic strains may arise from the level of variability within the symbiotic group. These findings do not invalidate the hypothesis that the clinical strains form a separate DNA relatedness group; they may reflect the diversity of the symbiotic group.

Although there appear to be some subsets within the symbiotic strain group, the degree of variability was very high and no subgroups could be defined. One apparent subset was made up of the $\mathrm{Hb}^{\mathrm{T}}$, Hm, C8404, C8406, NC162, D1, Tetuan, K81, HP88, K80, HV16, and HI strains (Table 2), which generally exhibited $>60 \%$ relatedness, and another apparent subset was made up of strains C1, Habana, Meg, HW79, HFR86, HL81, HF85, X1Nach, X1Lit, NZH, and T327, which generally exhibited $>65 \%$ relatedness. However, several strains exhibited about the same levels of relatedness to members of both subsets or higher levels of relatedness to members of the other subset than to some members of their own subset. The two symbiotic strains excluded from these subsets exhibited approximately equal levels of relatedness to members of both subsets. On the basis of these data it is not reasonable to subdivide the symbiotic strains.

Interpretation of the DNA relatedness data is complicated by the degree of experimental error involved. Although the estimates of DNA relatedness values for most reciprocal hybridizations were similar, some values varied more widely. However, analysis of the replicate data for reciprocal hybridizations revealed that there were no statistically significant differences for any pair. Estimates of levels of DNA relatedness in excess of $100 \%$ also indicate the extent of experimental error. The variations detected in this and other studies (24) show that care must be exercised in interpreting DNA relatedness data.

Conclusions. Despite the problems identified in this study, our phenotypic characterization and DNA relatedness data show that there are two distinct groups in the genus Photorhabdus. These groups are composed of the bacterial symbionts of entomogenous nematodes of the family Heterorhabditidae and of strains that have been isolated from human clinical specimens. The differences in the interactions of the symbiotic strains with various strains and species of nematodes $(8,25)$ and, to some extent, the DNA relatedness data suggest that the symbionts of nematodes are not a homogeneous group. However, in this study we did not identify phenotypic characters that differentiate organisms belonging to this group, even at the subspecies level. As the phenotypic differences of the symbiotic $P$. luminescens strains make it difficult to identify phenotypic characters that unambiguously differentiate the clinical group from the symbionts, it would be premature to define a new species for the clinical strains.

The challenge is to find the basis of the differences among the symbiotic Photorhabdus strains and to use that in constructing a valid taxonomy. There are a number of options that can be identified at this time. One involves further investigation of the symbiotic specificity by gnotobiological experiments. This approach requires a more accurate definition of the Heterorhabditis species (see Table 1 for difficulties in naming nematode hosts). Cross-breeding (17) and molecular methods (27) are currently being used to provide this definition. However, this is a functional taxonomy and will not necessarily reflect phylogenetic relationships.

An attempt to determine the phylogeny of the genera Photorhabdus and Xenorhabdus by comparing the 16S rRNA gene sequences of strains led Rainey et al. to suggest that these two genera are closely related because the genomic differences between the type species of the two genera were apparently not significantly higher than the genomic differences found in $\mathrm{Xe}$ norhabdus species (36). However, these authors acknowledged that their analyses produced variable results and that the algorithms and reference strains used did not reliably depict the relationships between Photorhabdus and Xenorhabdus strains. They suggested that additional sequence data, especially for $P$. luminescens, will be required to improve the analyses.

Another approach to determining the phylogenetic relationships within the genera Photorhabdus and Xenorhabdus and between these genera is analyzing the origins of genes acquired to exploit their current niches. The phylogenetic differences between the nematode hosts (31) and significant differences in the molecular nature of some characteristics (e.g., intracellular crystal proteins) suggest that similarities within and between the genera Photorhabdus and Xenorhabdus result from convergent evolution. Many of the characteristics that are common to the two genera and are coordinately affected by phase variation may have been acquired to enable the organisms to exploit the symbiotic niche. The suggestion (21) that molecular analysis of genes such as the protease, lipase, and intracellular crystal protein genes, etc. might be useful for distinguishing between Photorhabdus strains is well worth pursuing.

\section{ACKNOWLEDGMENTS}

We thank D. Colless, CSIRO Division of Entomology, for help with the principal-component analyses and J. Luciani for technical assistance. We thank E. Arteaga, E. Bonifassi, J. J. Farmer, Jr., P. Westerman, and M. Doucet for providing Photorhabdus strains.

We also thank the Institut National de la Recherche Agronomique and the Commonwealth Scientific and Industrial Research Organisation for financial support for exchanges between France and Australia.

\section{REFERENCES}

1. Abad, P., and C. Laumond. Personal communication.

1a.Akhurst, R. J. 1980. Morphological and functional dimorphism in Xenorhabdus spp., bacteria symbiotically associated with the insect pathogenic nematodes Neoaplectana and Heterorhabditis. J. Gen. Microbiol. 121:303-309.

2. Akhurst, R. J. 1982. Antibiotic activity of Xenorhabdus spp., bacteria symbiotically associated with insect pathogenic nematodes of the families Heterorhabditidae and Steinemematidae. J. Gen. Microbiol. 128:3061-3065. 
3. Akhurst, R. J. 1983. Taxonomic study of Xenorhabdus, a genus of bacteria symbiotically associated with insect-pathogenic nematodes. Int. J. Syst. Bacteriol. 33:38-45.

4. Akhurst, R. J. 1987. Use of starch gel electrophoresis in the taxonomy of Heterorhabditis (Nematoda: Heterorhabditidae). Nematologica 33:1-9.

5. Akhurst, R. J., R. A. Bedding, R. M. Bull, and D. R. J. Smith. 1992. An epizootic of Heterorhabditis spp. (Heterorhabditidae: Nematoda) in sugar cane scarabeids (Coleoptera). Fundam. Appl. Nematol. 15:71-73.

6. Akhurst, R. J., and N. E. Boemare. 1986. A non-luminescent strain of Xenorhabdus luminescens (Enterobacteriaceae). J. Gen. Microbiol. 132:19171922.

7. Akhurst, R. J., and N. E. Boemare. 1988. A numerical taxonomic study of the genus Xenorhabdus (Enterobacteriaceae) and proposed elevation of the subspecies of $X$. nematophilus to species. J. Gen. Microbiol. 134:751-761.

8. Akhurst, R. J., and N. E. Boemare. 1990. Biology and taxonomy of Xenorhabdus, p. 75-90. In R. R. Gaugler and H. K. Kaya (ed.), Entomopathogenic nematodes in biological control. CRC Press, Boca Raton, Fla.

9. Arteaga, E. M. Personal communication.

10. Arteaga-Hernandez, E. M., and Z. Mracek. 1984. Heterorhabditis heliothidis, a parasite of insect pests in Cuba. Fol. Parasitol. (Prague) 31:11-17.

11. Bedding, R. A. 1981 . Low cost in vitro mass production of Neoaplectana and Heterorhabditis species (Nematoda) for field control of insect pests. Nematologica 27:109-114.

12. Bleakley, B., and K. H. Nealson. 1988. Characterization of primary and secondary forms of Xenorhabdus luminescens strain Hm. FEMS Microbiol. Ecol. 53:241-250.

13. Boemare, N. E., and R. J. Akhurst. 1988. Biochemical and physiological characterization of colony form variants in Xenorhabdus spp. (Enterobacte riaceae). J. Gen. Microbiol. 134:1835-1845.

14. Boemare, N. E., R. J. Akhurst, and R. G. Mourant. 1993. DNA relatednes between Xenorhabdus spp. (Enterobacteriaceae), symbiotic bacteria of entomopathogenic nematodes, and a proposal to transfer Xenorhabdus luminescens to a new genus, Photorhabdus gen. nov. Int. J. Syst. Bacteriol. 43:249255 .

15. Bonifassi, E., and H. Mauleon. Personal communication.

16. Deseo, K. V. Personal communication.

17. Dix, I., A. M. Burnell, C. T. Griffin, S. A. Joyce, M. J. Nugent, and M. J Downes. 1992. The identification of biological species in the genus Hetero rhabditis (Nematoda: Heterorhabditidae) by cross-breeding second generation amphimictic adults. Parasitology 1104:509-518.

18. Doucet, M. Personal communication.

19. Ehlers, R.-U. 1991. Interactions in the entomopathogenic nematode-bacteria complex Steinernema/Heterorhabditis-Xenorhabdus. Int. Organ. Biol. Control/West. Paleartic Reg. Sect. Bull. 14:36-44.

20. Farmer, J. J., J. H. Jorgensen, P. A. Grimont, R. J. Akhurst, G. O. Poinar, E. Ageron, G. V. Pierce, J. A. Smith, G. P. Carter, K. L. Wilson, and F. W. Hickman-Brenner. 1989. Xenorhabdus luminescens (DNA hybridization group 5) from human clinical specimens. J. Clin. Microbiol. 27:1594-1602.

21. Forst, S., and K. Nealson. 1996. Molecular biology of the symbiotic-pathogenic bacteria Xenorhabdus spp. and Photorhabdus spp. Microbiol. Rev. 60:21-43.

22. Gerritsen, L. J. M. G. de Raay, and P. H. Smits. 1992. Characterization of form variants of Xenorhabdus luminescens. Appl. Environ. Microbiol. 58: 1975-1979.

23. Gerritsen, L. J. M., and P. H. Smits. 1993. Variation in pathogenicity of recombinations of Heterorhabditis and Xenorhabdus luminescens strains. Fundam. Appl. Nematol. 16:367-373.
24. Grimont, P. A., A. G. Steigerwalt, N. E. Boemare, F. W. Hickman-Brenner, C. Deval, F. Grimont, and D. Brenner. 1984. Deoxyribonucleic acid relatedness and phenotypic study of the genus Xenorhabdus. Int. J. Syst. Bacteriol. 34:378-388.

25. Han, R., W. M. Wouts, and L. Li. 1990. Development of Heterorhabditis spp strains as characteristics of possible Xenorhabdus luminescens subspecies. Rev. Nematol. 13:411-415.

26. Hurlbert, R. E., J. Xu, and C. L. Small. 1989. Colonial and cellular polymorphism in Xenorhabdus luminescens. Appl. Environ. Microbiol. 55:11361143.

27. Joyce, S. A., A. M. Burnell, and T. O. Powers. 1994. Characterization of Heterorhabditis isolates by PCR amplification of segments of mtDNA and rRNA genes. J. Nematol. 26:260-270.

28. Khan, A., and W. M. Brooks. 1977. A chromogenic bioluminescent bacterium associated with the entomophilic nematode Chromonema heliothidis. J. Invertebr. Pathol. 29:253-261.

29. Maniatis, T., E. F. Fritsch, and J. Sambrook. 1982. Molecular cloning: a laboratory manual. Cold Spring Harbor Laboratory, Cold Spring Harbor, N.Y.

30. Poinar, G. O. 1990. Biology and taxonomy of Steinernematidae and Heterorhabditidae, p. 23-61. In R. R. Gaugler and H. K. Kaya (ed.), Entomopathogenic nematodes in biological control. CRC Press, Boca Raton, Fla.

31. Poinar, G. O. 1993. Origins and phylogenetic relationships of the entomophilic nematodes, Heterorhabditis and Steinernema. Fundam. Appl. Nematol. 16:333-338.

32. Poinar, G. O., and R. Georgis. 1990. Characterization and field application of Heterorhabditis bacteriophora strain HP88 (Heterorhabditidae: Rhabditida). Rev. Nematol. 13:387-393.

33. Poinar, G. O., T. Jackson, and M. Klein. 1987. Heterorhabditis megidis $\mathbf{s p . ~} \mathbf{n}$ (Heterorhabditidae: Rhabditida), parasitic in the japanese beetle, Popillia japonica (Scarabaeidae: Coleoptera), in Ohio. Proc. Helminthol. Soc. Wash. 54:53-59.

34. Poinar, G. O., G. M. Thomas, and R. Hess. 1977. Characteristics of the specific bacterium associated with Heterorhabditis bacteriophora (Heterorhabditidae: Rhabditida). Nematologica 23:97-102.

35. Pütz, J., F. Meinert, U. Wyss, R.-U. Ehlers, and E. Stackebrandt. 1990 Development and application of oligonucleotide probes for molecular identification of Xenorhabdus species. Appl. Environ. Microbiol. 56:181-186.

36. Rainey, F. A., R.-U. Ehlers, and E. Stackebrandt. 1995. Inability of the polyphasic approach to systematics to determine the relatedness of the genera Xenorhabdus and Photorhabdus. Int. J. Syst. Bacteriol. 45:379-381.

37. Smigielski, A. J., R. J. Akhurst, and N. E. Boemare. 1994. Phase variation in Xenorhabdus nematophilus and Photorhabdus luminescens: differences in respiratory activity and membrane energization. Appl. Environ. Microbiol. 60: $120-125$.

38. Smits, P. H and R.U. Ehlers. 1991. Identification of Heterorhabditis spp. by morphometric characters and RFLP and of their symbiotic bacteria Xenorhabdus spp. by species specific DNA probes. Int. Organ. Biol. Control/West. Paleartic Reg. Sect. Bull. 14:195-201.

39. Sneath, P. H. A., and R. R. Sokal. 1973. Numerical taxonomy. W. H. Freeman, San Francisco.

40. Thomas, G. M., and G. O. Poinar. 1979. Xenorhabdus gen. nov., a genus of entomopathogenic bacteria of the family Enterobacteriaceae. Int. J. Syst. Bacteriol. 29:352-360.

40a. Westermann, P. Personal communication.

41. Wouts, W. M. 1979. The biology and life cycle of a New Zealand population of $H$. heliothidis (Heterorhabditidae). Nematologica 25:191-202. 